\title{
sGC Stimulators and Activators
}

\author{
Heli Tolppanen ${ }^{1}$, Piotr Ponikowski ${ }^{2}$ \\ 1. Helsinki University Central Hospital, Helsinki, Finland \\ 2. Head of the Department of Heart Diseases, Wroclaw Medical University and Head of the Cardiology Department at the \\ Center for Heart Diseases at 4th Military Hospital, Wroclaw, Poland
}

\section{Corresponding author:}

Prof. Piotr Ponikowski, Head of the Department of Heart Diseases,

Wroclaw Medical University and Head of the Cardiology Department at the Center for Heart Diseases at 4th Military Hospital, Wroclaw, Poland.

Email: piotr.ponikowski@umed.wroc.pl

\begin{abstract}
Nitric oxide (NO)-soluble guanylate cyclase(sGC)-cGMP signalling is impaired in HF syndromes, which could predispose to vascular oxidative stress. Nitrates directly stimulate cGMP, but are limited by tolerance. Therapeutic targets that aim at increasing cGMP concentrations have therefore been explored. Recently, two classes of drugs have been discovered, the sGC activators and the SGC stimulators, which target two different redox states of SGC: the NO-sensitive reduced (ferrous) sGC and NO-insensitive oxidized (ferric) SGC, respectively. Cinaciguat is an activator and riociguat and vericiguat are sGC stimulators. Vericiguat is the most advanced agent in its clinical trial programme with two completed phase llb studies, SOCRATES -REDUCED in HFrEF and SOCRATES-PRESERVED in HFpEF, with mixed results on NT-proBNP. The ongoing VICTORIA trial in HFrEF will study 4,872 participants with a mortality/morbidity end-point and VITALITY HFpEF trial will study 735 participants, with a quality of life endpoint.
\end{abstract}

Keywords: heart failure; SGC activators; SGC stimulators; vericiguat

Citation: $\quad$ Tolppanen H, Ponikowski P. sGC Stimulators and Activators. International Cardiovascular Forum Journal. 2019;18:609.2-6 DOI: 10.17987/icfj.v18i0.609

\section{Introduction}

The nitric oxide (NO)-soluble guanylate cyclase(sGC)-cGMP cascade is one of the key regulatory pathways in cardiovascular physiology. In heart failure (HF), the NO-sGC-cGMP signaling is impaired mainly due to reduced NO bioavailability and the altered redox state of sGC, making it unresponsive to NO. These changes might be a major source of vascular oxidative stress in the course of HF.

Nitrates, which have traditionally been used to treat acute and chronic HF, and angina, act through this cascade by increasing free NO by directly stimulating cGMP. However, this upstream stimulation of available NO is limited by tolerance, and it causes reactive oxygen species production and endothelial dysfunction. Therapeutic targets that aim at increasing cGMP concentrations have therefore been explored (Figure 1). Recently, two classes of drugs have been discovered, the SGC activators and SGC stimulators, which target two different redox states of SGC: the NO-sensitive reduced (ferrous) SGC and NO-insensitive oxidized (ferric) SGC, respectively (Table 1).[1] Phosphodiesterase type 5 inhibitors (PDE5, such as sildenafil) also act in the same regulatory pathway, but downstream of adenylate cyclase by inhibiting the degradation of cGMP. Cinaciguat, riociguat and vericiguat are direct SGC activators that act independently of nitric oxide.
Physiology of cGMP and the NO-sGC-cGMP signaling cascade NO-sGC-cGMP signalling starts in the intact endothelium of blood vessels and the myocardium by hormonal and physical stimuli causing endothelial nitric oxide synthase (eNOS) to generate NO. NOS-derived NO diffuses to the neighbouring tissues, such as vascular smooth muscle cells or cardiomyocytes, where it binds to the cytosolic enzyme sGC. This NO-sGC binding catalyzes the conversion of guanosine triphosphate (GTP) to cGMP. cGMP activates protein kinase $G(P K G)$, and these together lead to the decrease in intracellular free calcium resulting in the relaxation of vascular smooth muscle cells as one major physiological effect in the cardiovascular system.[2-4]

The best established role of GCs is within the vessel wall and the myocardium, as the receptors of NO signalling are in vascular smooth muscle and in the myocardium, where the sGC expression is at its highest. In vascular smooth muscle cells and cardiac myocytes with SGC-derived cGMP production NO generation from vascular, endocardial, and intramyocardial capillary endothelial cells stimulates SGC in coronary vessel walls as well as directly in cardiomyocytes.[1,5,6] Experiments performed in animal models have shown cGMP deficiency to play a crucial role in the development of diastolic dysfunction, 


\begin{tabular}{|c|c|c|}
\hline & sGC Stimulator & sGC activator \\
\hline Defect & $\begin{array}{l}\text { Upstream of sGC: insufficient } \\
\text { sGC stimulation }\end{array}$ & $\begin{array}{l}\text { sGC itself defective: } \\
\text { sGC heme } \\
\text { dissociation }\end{array}$ \\
\hline $\begin{array}{l}\text { Causative } \\
\text { mechanism }\end{array}$ & $\begin{array}{l}\text { Endothelial dysfunction = } \\
\text { eNOS insufficiency } \\
\text { e.g.; owing to oxidative } \\
\text { stress, ADMA, inflammatory } \\
\text { activation }\end{array}$ & $\begin{array}{l}\text { Oxidative injury to } \\
\text { the heme group of } \\
\text { sGC }\end{array}$ \\
\hline Role of NO & $\begin{array}{l}\text { NO deficiency: } \\
\text { Reduced eNOS-derived } \\
\text { No bioavailability }\end{array}$ & $\begin{array}{l}\text { NO resistance: } \\
\text { Dysfunctional NO } \\
\text { receptor: sGC low } \\
\text { despite bioavailable } \\
\text { NO }\end{array}$ \\
\hline $\begin{array}{l}\text { Molecular } \\
\text { principle }\end{array}$ & $\begin{array}{l}\text { NO-independent sGC } \\
\text { stimulation by mimicking NO }\end{array}$ & $\begin{array}{l}\text { NO-independent } \\
\text { sGC activation by } \\
\text { mimicking reduced } \\
\text { heme + prolongation } \\
\text { of sGC protein half- } \\
\text { life under oxidative } \\
\text { stress }\end{array}$ \\
\hline
\end{tabular}

Reproduced from (1) with permission

reduced cardiac output and increased afterload.[4] In addition to the lusitropic effects of cGMP, it reveals also important antiinflammatory and antifibrotic effects.[7]

The cGMP activity within the cell is regulated by both NOdependent and by NO-independent pathways. The NOdependent cGMP pool is regulated by NO availability and the activity of SGC. PDE5 inhibition (e.g. sildenafil) increases the cytoplasmic levels of cGMP by inhibiting its degradation. This process is limited to tissues, in which the PDE5 is up-regulated, such as the corpus cavernosum and pulmonary vasculature, and may be under-expressed in myocardium. The NOindependent regulatory pathways include natriuretic peptides, beta-adrenergic stimulation, prostacyclin-cAMP pathway and endothelial pathways.

\section{Role of the NO-sGC-cGMP cascade in heart failure}

The NO-sGC-cGMP signaling pathway plays a major role in protection against myocardial injury, ventricular remodeling, and the cardio-renal syndrome.[1] HF may be viewed as a syndrome in which NO deficiency results in an insufficient stimulation of sGC in the systemic, coronary, pulmonary, and renal vasculature, leading to the impaired protection against ischaemia/reperfusion injury, myocardial dysfunction, adverse left ventricular remodeling, and the cardio-renal syndrome.[1,8]

NO availability and functionality of SGC depends on the redox status. In HF the endogenous levels of $\mathrm{NO}$ are decreased due to various derangements in NO-sGC-cGMP signalling, such as a down-regulation of the endothelial NO synthase (eNOS), inactivation of $\mathrm{NO}$ by superoxide anions, increased plasma concentrations of an endogenous eNOS inhibitor, and an altered redox state of sGC due to oxidative stress.[1] All these

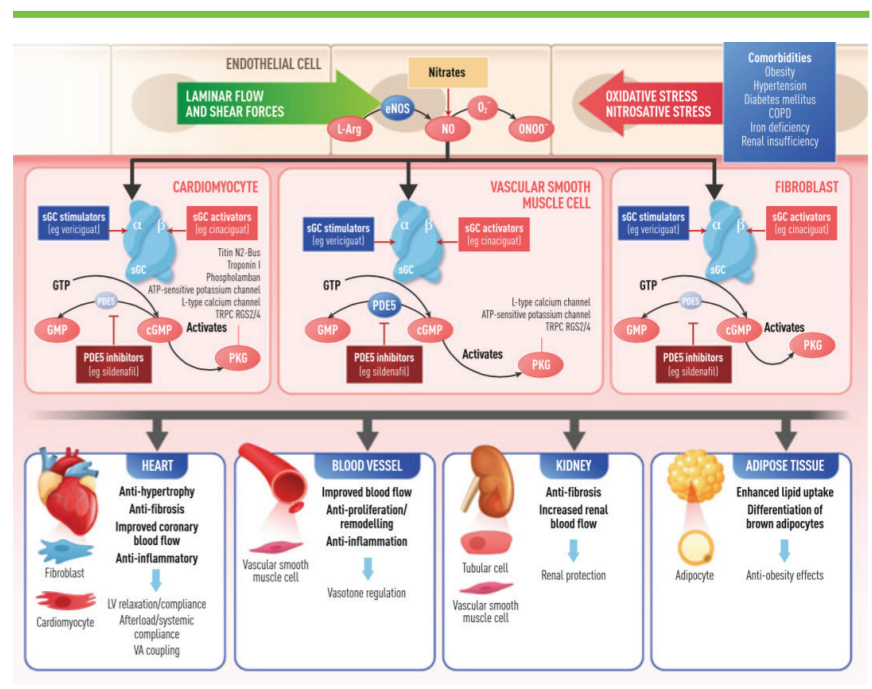

Figure 1. sGC-derived cGMP generation in various cell types couples endothelial NO synthesis to function of organs including the heart and kidneys. CGMP is a second messenger of crucial importance to organ function. Reduced cGMP availability caused by NO deficiency due to endothelial dysfunction can be actively restored by SGC stimulation in smooth muscle cells, cardiomyocytes or fibroblasts, whereas PDE5 inhibition can only inhibit cGMP degradation. Restoration of cGMP signaling has beneficial effects in hearts, blood vessels, and kidneys and could also impact on adipose tissue. Legend: L-Arg = L-Arginine, $\mathrm{O} 2$ = peroxide, $\mathrm{ONOO}-=$ peroxynitrite, $\mathrm{TRPC}=$ transient receptor potential channels

abnormalities result in reduced levels of the NO-sensitive form of SGC. Neurohormonal activation and release of inflammatory mediators in HF may further reduce NO bioavailability, ultimately leading to an insufficient stimulation of the NO receptor, SGC, and subsequently the diminished production of its second messenger cGMP.[9,10] Reduced cGMP availability leads to endothelial dysfunction, vasoconstriction, vascular stiffness and adverse remodeling, and decreased renal and coronary blood flow with increasing impairment of respective organ function.[1,4,11] Dysregulation of the NO-cGMP-pathway by inflammation and oxidative stress resulting in endothelial dysfunction also negatively affects coronary perfusion[2,12] and promotes myocardial damage.[12]

In HFrEF, cGMP deficiency leads to impaired endotheliumdependent regulation of vessel tone, resulting in an increased afterload and impaired myocardial microcirculation. cGMP dependent PKG modulates pathological $\mathrm{Ca} 2+$ signalling involved in myocardial hypertrophy.[13] HFpEF, in particular, is an inflammatory condition accompanied in many patients by metabolic syndrome, obesity, diabetes mellitus (DM), arterial hypertension, and chronic obstructive pulmonary disease (COPD). The NO-sGC-cGMP axis plays a major role in the relaxation abnormalities that occur in HFpEF. Titin is a large cardiomyocyte cytoskeletal protein that modulates passive tension and stiffness of myocardial fibres. When titin is phosphorylated by cGMP-dependent protein kinase G (PKG), myocardial fibres stretch appropriately and allow ventricular relaxation and diastolic filling as well as recoil.[14,15] Indeed, hypophosphorylation of titin results in increased myocardial 
stiffness that leads to suboptimal ventricular filling and decreased cardiac output. Since dysfunction of the NOsGC-cGMP axis also leads to vasoconstriction and vascular stiffness, the combination of impaired ventricular relaxation and increased afterload renders HF patients symptomatic during an increased demand, such as during exercise.[12] Indeed, impaired exercise-induced NO release may also contribute to reduced exercise capacity.[16] The increased myocardial stiffness in HFpEF patients was shown to be decreased after administration of PKG.[17] However, the results with the administration of PDE5 inhibitor (sildenafil) have been disappointing in this context in HFpEF patients. $[18,19]$

Secondary pulmonary hypertension $(\mathrm{PH})$ in patients with left heart disease is an indicator of persistently increased LV filling pressures. As many as 33 to $48 \%$ of HFrEF and up to $83 \%$ of HFpEF patients may have secondary $\mathrm{PH}$, and $\mathrm{PH}$ is associated with poor outcomes in these patients.[20,21] In addition to passive backward failure, a vasoreactive component may, in certain cases, aggravate the resulting $\mathrm{PH} .[22]$ The effects of riociguat and sildenafil were studied in an animal model with transverse aortic constriction-induced left ventricular hypertrophy and dysfunction, and secondary $\mathrm{PH}$. Riociguat had a more pronounced effect on vascular remodeling compared to sildenafil. Treatment with riociguat and sildenafil maintained LV and RV function and decreased PVR and RV pressure, while in placebo treated animals LV and RV function deteriorated.[23] However, the clinical results for the PDE5 inhibitors came out negative, possibly due to lack of PDE5 overexpression and/or insufficient proximal SGC stimulation. In contrast, high SGC expression in the cardiac muscle and enhanced sGC-derived cGMP levels even in the absence of $\mathrm{NO}$ indicate a promising potential for SGC stimulators. In patients with $\mathrm{PH}$ associated with systolic left ventricular dysfunction, reduced PVR and SVR, improved stroke volume and cardiac index as well as improved quality of life (QoL) were seen when the treatment with riociguat was administered.[24]

\section{Action of SGC stimulators and SGC activators}

sGC consists of an $\alpha / \beta$-heterodimeric protein with a prosthetic ferrous heme group. The heme group can exist in different redox states, which, in addition to its NO-sensing capability, may enable SGC to modulate intracellular redox homeostasis. The presence of a reduced $\mathrm{Fe}^{2+}$ (ferrous) heme group is crucial for NO-sensing and NO-dependent sGC stimulation. Oxidative stress favours heme-free SGC, which is unable to respond to NO, and can be regarded as a dysfunctional form of the enzyme. Oxidative stress may make SGC unresponsive to endogenous and exogenous NO either through reducing NO bioavailability or by altering the redox state of sGC.[25] In $\mathrm{HF}$, endothelial dysfunction and an inflammatory state lead to increased formation of reactive oxygen species, reduced NO bioavailability, and shifts in SGC toward the oxidized and NOunresponsive, heme-free form of sGC.[26] sGC stimulators target the heme-containing non-oxidized form of sGC by binding on the regulatory domain and triggering cGMP production. The SGC stimulators have a dual mode of action; they sensitize sGC to low levels of $\mathrm{NO}$ and can stimulate sGC directly in the absence of any endogenous NO. The sGC stimulators work NO-independently but their efficacy is further enhanced when endogenous NO is present, even at low concentrations.
[1] By contrast, sGC activators specifically activate the NOunresponsive, heme-free form of the enzyme irrespective of NO bioavailability.[25]

\section{sGC activators: cinaciguat}

Cinaciguat is a potent and selective sGC activator, which acts on SGC in its oxidized $\left(\mathrm{Fe}^{3+}\right)$ state and even the heme free form, independently of NO. The oxidation or absence of the heme moiety increases the effect of cinaciguat on the sGC causing a significant cGMP increase.[25,26] Animal studies with cinaciguat have shown arterial and venous vasodilatation and antihypertrophic and antifibrotic effects.

The first clinical trial with cinaciguat confirmed haemodynamic efficacy, with a reduction in post- and preload and a secondary increase in cardiac output, while preserving renal function. The COMPOSE trial compared multiple doses of cinaciguat in patients with acute HF with LVEF $<40 \%$ and an elevated pulmonary capillary wedge pressure (PCWP) $>18 \mathrm{mmHg}$. [27] High doses (50, 100 and $150 \mathrm{mcg} / \mathrm{h}$ ) were associated with an excessive reduction in blood pressure, leading to premature discontinuation of the study. A parallel study included patients with chronic HF with elevated PCWP $\geq 18$ $\mathrm{mmHg}$, and the effects of cinaciguat were evaluated using invasive haemodynamic measurements.[28] In patients treated with cinaciguat, significant decreases in PCWP and right atrial pressure, systemic and pulmonary vascular resistance, and a significant increase in cardiac index were observed. A high rate of hypotension also led to the premature termination of this study. Subsequently, the study was criticized, as with other studies with vasodilators, because the baseline blood pressure was not high enough, ultimately biasing the estimate of the clinical potential of the molecule.[29]

\section{Riociguat (sGS stimulator)}

Riociguat is a novel potent sGC stimulator, which was mainly developed for primary pulmonary artery hypertension (PAH), but also for PAH caused by left-heart disease. Its use is currently approved in the treatment of primary $\mathrm{PAH}$ and inoperable chronic thromboembolic pulmonary hypertension (CTEPH).

Two trials have been published in patients with HF. The small phase Ila DILATE-1a study showed in 39 patients with HFpEF and $\mathrm{PAH}$, that a single oral dose of riociguat decreased systolic blood pressure, increased systolic volume, but did not alter filling pressures or mean pulmonary arterial pressure.[29] The LEPHT trial then included approximately 200 patients with chronic HF with LVEF $<45 \%$ with mean pulmonary arterial pressure $\geq 25 \mathrm{mmHg}$ (confirmed by right heart catheterization). [30] Patients were randomized into four groups: placebo and three riociguat doses for 16 weeks. The primary outcome of decrease in mean pulmonary artery pressure was not significant, whereas significant improvements were observed in secondary end-points of increased cardiac index, and decreased systemic and pulmonary vascular resistance (invasive haemodynamic measurements).

\section{Vericiguat (sGC stimulator)}

The first experiences with an SGC stimulator in patients with HF and secondary $\mathrm{PH}$ encouraged the continued investigation of this novel drug class in HF at low doses. For further studies in HF, the 
once daily compound vericiguat was chosen due to its optimized pharmacokinetic profile. Vericiguat was investigated in two phase llb studies in HFrEF (SOCRATES -REDUCED) and HFpEF (SOCRATES-PRESERVED), in which patients were included during a hospitalization for acute HF, and the end-point was a decrease in circulating natriuretic peptides. The SOCRATESPRESERVED randomized HFpEF patients (LVEF $\geq 45 \%$ ) into 5 parallel dose arms or placebo for 12 weeks to characterize safety, tolerability, and pharmacologic effects. The study was negative in its primary outcomes of decreasing levels of natriuretic peptides or reducing left atrial volume.[31] The SOCRATES-REDUCED showed a statistically positive effect on NT-proBNP only with the highest doses in secondary analysis[32], and the agent is currently being tested in a phase III study for HFrEF, the ongoing VICTORIA trial[33], with the primary hypothesis that vericiguat is superior to placebo in increasing the time to first occurrence of the composite of cardiovascular death or HF hospitalization in a planned 4,872 participants with HFrEF with results expected in 2020. The VITALITY-HFpEF trial plans to assess whether treatment with vericiguat $10 \mathrm{mg}$ or $15 \mathrm{mg}$ in patients with HFpEF improves the KCCQ PLS (Kansas City Cardiomyopathy Questionnaire Physical limitation score) compared to placebo after 24 weeks of treatment in a planned 735 participants, with results also expected in 2020.[34]

\section{Conclusions}

Experimental and preliminary clinical data suggest that SGC stimulators are promising molecules to be studied for a potential role in the future HF treatment strategy. The results of ongoing morbidity and mortality trial with vericiguat in patients HFrEF are expected.

\section{Declarations of interest}

The authors declare no conflict of interest.

\section{Acknowledgements}

The authors state that they abide by the authors' responsibilities and ethical publishing guidelines of the International Cardiovascular Forum Journal.

\section{References}

1. Gheorghiade M, Marti CN, Sabbah HN et al. Soluble guanylate cyclase: a potential therapeutic target for heart failure. Heart Fail Rev 2013;18:123-34.

2. Paulus WJ, Bronzwaer JG (2004) Nitric oxide's role in the heart: control of beating or breathing? Am J Physiol Heart Circ Physiol 287(1):H8-13

3. Mohan P, Brutsaert DL, Paulus WJ, Sys SU (1996) Myocardial contractile response to nitric oxide and cGMP. Circulation 93(6):1223-1229

4. Buys ES, Sips P, Vermeersch P, Raher MJ, Rogge E, Ichinose F, Dewerchin M, Bloch KD, Janssens S, Brouckaert P (2008) Gender-specific hypertension and responsiveness to nitric oxide in sGCalpha1 knockout mice. Cardiovasc Res 79(1):179-186

5. Lim SL, Lam CS, Segers VF, Brutsaert DL, De Keulenaer GW (2015) Cardiac endothelium- myocyte interaction: clinical opportunities for new heart failure therapies regardless of ejection fraction. Eur Heart J 36(31):2050-2060.

6. Noireaud J, Andriantsitohaina R (2014) Recent insights in the paracrine modulation of cardiomyocyte contractility by cardiac endothelial cells. Biomed Res Int 2014:923805.

7. Ahluwalia A, Foster P, Scotland RS, McLean PG, Mathur A, Perretti M, Moncada S, Hobbs AJ (2004) Antiinflammatory activity of soluble guanylate cyclase: cGMP-dependent down-regulation of P-selectin expression and leukocyte recruitment. Proc Natl Acad Sci USA 101 (5):1386-1391.

8. Jones SP, Greer JJ, van Haperen R, Duncker DJ, de Crom R, Lefer DJ (2003) Endothelial nitric oxide synthase overexpression attenuates congestive heart failure in mice. Proc Natl Acad Sci USA 100(8):4891-4896.

9. Vanhoutte PM, Shimokawa H, Tang EH, Feletou M (2009) Endothelial dysfunction and vascular disease. Acta Physiol (Oxf) 196(2):193-222
10. Schmidt HH, Hofmann F, Stasch JP (2009) Handbook of experimental pharmacology. 191 cGMP generators, effectors and therapeuticimplications. Preface. Handb Exp Pharmacol 191:v-vi

11. Franssen $C$, Chen S, Unger A, Korkmaz HI, De Keulenaer GW, Tschope $C$, Leite-Moreira AF, Musters R, Niessen HW, Linke WA, Paulus WJ, Hamdan $\mathrm{N}$ (2016) Myocardial microvascular inflammatory endothelial activation in heart failure with preserved ejection fraction. JACC Heart Fail 4(4):312-324

12. Greene SJ, Gheorghiade M, Borlaug BA, Pieske B, Vaduganathan M, Burnett JC Jr, Roessig L, Stasch JP, Solomon SD, Paulus WJ, Butler J (2013) The cGMP signaling pathway as a therapeutic target in heart failure with preserved ejection fraction. J Am Heart Assoc 2(6):e000536.

13. Hammond J, Balligand JL (2012) Nitric oxide synthase and cyclic GMP signaling in cardiac myocytes: from contractility to remodeling. J Mol Cell Cardiol 52(2):330-340.

14. Hamdani N, Krysiak J, Kreusser MM, Neef S, Dos Remedios CG, Maier LS, Kruger M, Backs J, Linke WA (2013) Crucial role for $\mathrm{Ca} 2(+) /$ calmodulin-dependent protein kinase-II in regulating diastolic stress of normal and failing hearts via titin phosphorylation. Circ Res 112

15. Linke WA, Hamdani N (2014) Gigantic business: titin properties and function through thick and thin. Circ Res 114(6):1052-1068

16. Maxwell AJ, Schauble E, Bernstein D, Cooke JP (1998) Limb blood flow during exercise is dependent on nitric oxide. Circulation 98(4):369-374

17. van Heerebeek L, Hamdani N, Falcao-Pires I, Leite-Moreira AF, Begieneman MP, Bronzwaer JG, van der Velden J, Stienen GJ, Laarman GJ, Somsen A, Verheugt FW, Niessen HW, Paulus WJ (2012) Low myocardial protein kinase $\mathrm{G}$ activity in heart failure with preserved ejection fraction. Circulation 126(7):830-839.

18. Redfield MM, Chen HH, Borlaug BA, et al. (2013) Effect of phosphodiesterase-5 inhibition on exercise capacity and clinical status in heart failure with preserved ejection fraction: a randomized clinical trial. JAMA 309(12):1268-1277.

19. Hoendermis ES, Liu LC, Hummel YM, van der Meer P, de Boer RA, Berge RM, van Veldhuisen DJ, Voors AA (2015) Effects of sildenafil on invasive haemodynamics and exercise capacity in heart failure patients with preserved ejection fraction and pulmonary hypertension: a randomized controlled trial. Eur Heart J 36(38):2565-2573.

20. Galie N, Humbert M, Vachiery JL, et al.(2016) 2015 ESC/ERS guidelines for the diagnosis and treatment of pulmonary hypertension: the joint task force for the diagnosis and treatment of pulmonary hypertension of the European Society of Cardiology (ESC) and the European Respiratory Society (ERS): endorsed by: Association for European Paediatric and Congenital Cardiology (AEPC), International Society for Heart and Lung Transplantation (ISHLT). Eur Heart J. 2016 Jan 1;37(1):67-119. doi: 10.1093/ eurheartj/ehv317. Epub 2015 Aug 29.

21. Damy T, Goode KM, Kallvikbacka-Bennett A, Lewinter C, Hobkirk J, Nikitin NP, Dubois-Rande JL, Hittinger L, Clark AL, Cleland JG (2010) Determinants and prognostic value of pulmonary arterial pressure in patients with chronic heart failure. Eur Heart J 31(18):2280-2290.

22. Lam CSP, Voors AA, de Boer RA, Solomon SD, van Veldhuisen DJ. Heart failure with preserved ejection fraction: from mechanisms to therapies. Eur Heart J. 2018 Aug 7;39(30):2780-2792. doi: 10.1093/eurheartj/ehy301.

23. Pradhan K, Sydykov A, Tian X, et al. (2016) Soluble guanylate cyclase stimulator riociguat and phosphodiesterase 5 inhibitor sildenafil ameliorate pulmonary hypertension due to left heart disease in mice. Int $\mathrm{J}$ Cardiol. 2016 Aug 1;216:85-91. doi: 10.1016/j.ijcard.2016.04.098.

24. Bonderman D, Ghio S, Felix SB et al. Riociguat for patients with pulmonary hypertension caused by systolic left ventricular dysfunction: a phase IIb double-blind, randomized, placebo-controlled, dose-ranging hemodynamic study. Circulation 2013;128:502-11.

25. Evgenov OV, Pacher P, Schmidt PM, Hasko G, Schmidt HH, Stasch JP (2006) NO-independent stimulators and activators of soluble guanylate cyclase: discovery and therapeutic potential. Nat Rev Drug Discov 5(9):755-768.

26. Munzel T, Gori T, Bruno RM, Taddei S (2010) Is oxidative stress a therapeutic target in cardiovascular disease? Eur Heart J 31:2741-2748

27. Gheorghiade M, Greene SJ, Filippatos G, Erdmann E, Ferrari R, Levy PD, Maggioni A, Nowack C, Mebazaa A, Investigators C, Coordinators Cinaciguat, a soluble guanylate cyclase activator: results from the randomized, controlled, phase Ilb COMPOSE programme in acute heart failure syndromes. Eur J Heart Fail. 2012;14(9):1056-1066.

28. Erdmann E, Semigran MJ, Nieminen MS, Gheorghiade M, Agrawal R, Mitrovic V, Mebazaa A. Cinaciguat, a soluble guanylate cyclase activator, unloads the heart but also causes hypotension in acute decompensated heart failure. Eur Heart J. 2013;34(1):57-67.

29. Levy PD, Laribi S, Mebazaa A. Vasodilators in Acute Heart Failure: Review of the Latest Studies. Curr Emerg Hosp Med Rep. 2014;2(2):126-132.

30. Bonderman D, Ghio S, Felix SB, Ghofrani HA, Michelakis E, Mitrovic V, Oudiz RJ, Boateng F, Scalise AV, Roessig L, Semigran MJ, Left Ventricular Systolic Dysfunction Associated With Pulmonary Hypertension Riocigua Trial Study G. Riociguat for patients with pulmonary hypertension caused by systolic left ventricular dysfunction: a phase Ilb double-blind, randomized, placebo-controlled, dose-ranging hemodynamic study. Circulation. 2013;128(5):502-511. 
31. Pieske B, Maggioni AP, Lam CSP, Pieske-Kraigher E, Filippatos G, Butler J, Ponikowski P, Shah SJ, Solomon SD, Scalise AV, Mueller K, Roessig L, Gheorghiade M. Vericiguat in patients with worsening chronic heart failure and preserved ejection fraction: results of the SOluble guanylate Cyclase stimulatoR in heArT failurE patientS with PRESERVED EF (SOCRATESPRESERVED) study. Eur Heart J. 2017;38(15):1119-1127.

32. Gheorghiade M, Greene SJ, Butler J, Filippatos G, Lam CS, Maggioni AP, Ponikowski P, Shah SJ, Solomon SD, Kraigher-Krainer E, Samano ET, Muller K, Roessig L, Pieske B, Investigators S-R, Coordinators. Effect of Vericiguat, a Soluble Guanylate Cyclase Stimulator, on Natriuretic Peptide Levels in Patients With Worsening Chronic Heart Failure and Reduced Ejection Fraction: The SOCRATES-REDUCED Randomized Trial. JAMA. 2015;314(21):2251-2262.

33. Armstrong PW, Roessig L, Patel MJ, Anstrom KJ, Butler J, Voors AA, Lam CSP, Ponikowski P, Temple T, Pieske B, Ezekowitz J, Hernandez AF, Koglin J, O'Connor CM. A Multicenter, Randomized, Double-Blind, PlaceboControlled Trial of the Efficacy and Safety of the Oral Soluble Guanylate Cyclase Stimulator: The VICTORIA Trial. JACC Heart Fail. 2018 Feb;6(2):96104. doi: 10.1016/j.jchf.2017.08.013.

34. https://clinicaltrials.gov/ct2/show/NCT03547583

35. Shewan LG, Coats AJS, Henein MY. Authors' Responsibilities and Ethical Publishing. International Cardiovascular Forum Journal 2018;13:3-4, DOI: 10.17987/icfj.v13i0.525 